\title{
Transient Air-Water Flow and Air Demand following an Opening Outlet Gate
}

\author{
James Yang $\mathbb{D},{ }^{1,2}$ Ting Liu, ${ }^{3}$ Wenhong Dai, ${ }^{4}$ and Penghua Teng $\mathbb{D}^{1}$ \\ ${ }^{1}$ Hydraulic Engineering, Royal Institute of Technology (KTH), 10044 Stockholm, Sweden \\ ${ }^{2}$ R\&D Älvkarleby Laboratory, Vattenfall AB, 81426 Älvkarleby, Sweden \\ ${ }^{3}$ Tyrens AB, 11886 Stockholm, Sweden \\ ${ }^{4}$ Water Conservancy \& Hydropower Engineering, Hohai University, Nanjing, China
}

Correspondence should be addressed to James Yang; james.yang@vattenfall.com

Received 30 September 2017; Revised 30 December 2017; Accepted 14 January 2018; Published 1 March 2018

Academic Editor: Dimitrios E. Manolakos

Copyright (c) 2018 James Yang et al. This is an open access article distributed under the Creative Commons Attribution License, which permits unrestricted use, distribution, and reproduction in any medium, provided the original work is properly cited.

\begin{abstract}
In Sweden, the dam-safety guidelines call for an overhaul of many existing bottom outlets. During the opening of an outlet gate, understanding the transient air-water flow is essential for its safe operation, especially under submerged tailwater conditions. Threedimensional CFD simulations are undertaken to examine air-water flow behaviors at both free and submerged outflows. The gate, hoisted by wire ropes and powered by AC, opens at a constant speed. A mesh is adapted to follow the gate movement. At the free outflow, the CFD simulations and model tests agree well in terms of outlet discharge capacity. Larger air vents lead to more air supply; the increment becomes, however, limited if the vent area is larger than $10 \mathrm{~m}^{2}$. At the submerged outflow, a hydraulic jump builds up in the conduit when the gate reaches approximately $45 \%$ of its full opening. The discharge is affected by the tailwater and slightly by the flow with the hydraulic jump. The flow features strong turbulent mixing of air and water, with build-up and break-up of air pockets and collisions of defragmented water bodies. The air demand rate is several times as much as required by steady-state hydraulic jump with free surface.
\end{abstract}

\section{Introduction}

In the existing hydropower dams, many flood discharge structures are bottom outlets that feature, depending upon the tailwater conditions, either free surface or pressurized flow in the downstream conduits. The conduit length ranges usually from 30 to $150 \mathrm{~m}$. The flow through the outlet conduits is controlled by either a segment or bulkhead gate which is required to operate under varied hydraulic conditions. Dath and Mathiesen [1] summarized the situation in Sweden and reported the observed incidents that were related to air entrainment. The need for research to understand and resolve the problems was also emphasized.

To fulfill normal operation requirements, sufficient air supply is one of the essential aspects of the outlets. A high velocity flow occurring downstream of the gate causes air entrainment, resulting in subatmospheric air pressure in the conduit. In a conduit flowing partially full, water surface disturbances lead to air entrainment and the drag of the water surface generates an air flow that must be accounted for. The total volume flow of air equals the sum of the air that is insufflated into the flow and that which flows above the water surface. If a hydraulic jump occurs in the conduit, the local air entrainment is due to surface and velocity discontinuity characterized by intensive turbulence productions [2-4].

Though bottom outlets are less common in numbers than the surface-type spillways, their unique functions in terms of reservoir emptying, sediment flashing, and so on cannot be replaced. The bottom outlets in Sweden were built 40-60 years ago; many of them were designed only for use during the dam construction period. This means that they only experienced flow discharges at low reservoir water levels, but never at the full retention levels. Dam refurbishment and changed operation procedures for power plants call now for an overhaul of the bottom outlets. In some cases, the dam body and foundation reinforcement requires drawing down or even emptying the reservoir, which is only possible to achieve through the outlets. 
Governed by reservoir operation requirements, the outlet gates have been more frequently operated than before. Varying hydraulic conditions under which the gates operate also give rise to dramatically different flow patterns in the conduits, which is mainly due to tailwater variations. Understanding the features of both water and air flows in the outlets contributes undoubtedly to their safe operations.

\section{Literature Review}

For flows in a partially filled conduit, the air demand is dependent on both water and air flow conditions in it. For either small or large outlets, flow-induced air motions cannot be neglected. Tunnel lengths have usually a bearing on the air flow rate downstream of an outlet gate [5]. Serret [6] summarized the experiences of air supply in the Spanish bottom outlets. In a 1:15 scale model, Schneider et al. [7] investigated the Kárahnjúkar bottom outlet, Iceland, in which the air demand was determined at fixed gate openings and comparisons were made with theoretical results.

As for hydraulic jump in a conduit, the amount of entrained air is closely related to the Froude number, defined as $\mathrm{F}=V_{1} /\left(g h_{1}\right)^{0.5}$, where $V_{1}$ and $h_{1}$ are flow velocity and water depth upstream of the hydraulic jump and $g=$ gravity acceleration. A general expression of air flow rate $Q_{a}$ in relation to water flow rate $Q_{w}$ reads

$$
\beta=\frac{Q_{a}}{Q_{w}}=m \cdot(F-1)^{n}
$$

in which $m$ and $n$ are constants. Table 1 lists the frequently cited formulas [8-10].

Comparisons show that, depending on $\mathrm{F}$ values, there are nonnegligible differences between the formulas for the air demand prediction, which is presumably due to differences in conduit configurations and downstream exit conditions [16-18]. In physical hydraulic modelling, scale effects of air entrainment are substantial and corrections are needed to reasonably approximate prototype situations $[19,20]$.

For given flow conditions, air supply to a bottom outlet is governed by air vent dimensions and singular (form) losses of the air passage. If the singular losses are large or the vent area is small, air would also be supplied from the tunnel outlet [21]. Najafi and Zarrati [22] performed both physical and numerical modelling of air demand at fixed gate openings. For the scale model examined, the agreement between the two approaches is good. Zounemat-Kermani and Scholz [23] developed an adaptive neuro-fuzzy inference system for computing air demand in low-head outlets. Ma et al. [24] simulated water and air flows in an outlet during the closing of its segment gate; their focus was however on the water flow and not on the air flow. Similar numerical modelling was performed by Dargahi [25], in which the discharge characteristics of a bottom outlet with a moving gate were discussed.

The preceding studies focused on air flow associated with hydraulic jumps under steady-state flow conditions, either free or submerged. Those studies have contributed in one way or another to the understanding of the flow as well as air entrainment in steady-state hydraulic jumps. Under

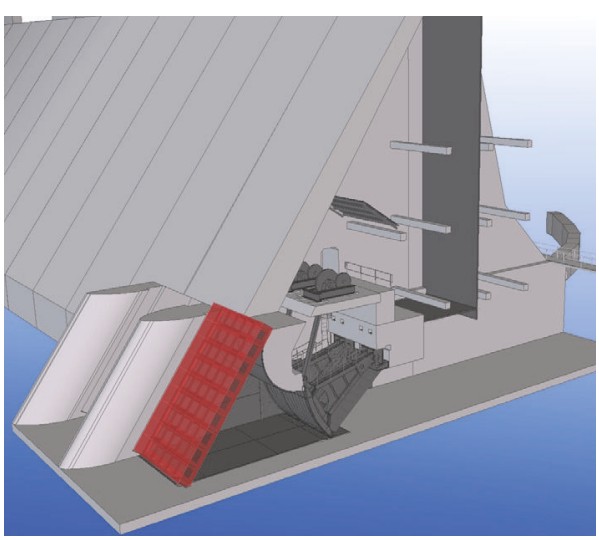

FIGURE 1: Layout of the bottom outlet with a radial gate and a sloping bulkhead gate for maintenance.

submerged tailwater conditions, computations of transients and the resulting air demand are rare; limited information is available in the literature. Depending on the gate opening speed, hysteretic effects might exist of the gate movement on the hydraulic jump formation and air demand if the conduit is under water; entrained air is trapped featuring break-up and coalescence of air pockets.

Based on an existing bottom outlet in a buttress dam, computational fluid dynamics (CFD) simulations of twophase flow are performed in three dimensions, with the radial gate moving from its closed position and to the full opening. An adaptive mesh is generated to follow the gate movement. The main purpose of the study is to assess the transient waterair flows under both free and submerged tailwater conditions. This helps understand the dynamic feature of the flow, which is essential to operational safety of the outlet.

\section{Research Background}

The bottom outlet examined in the study is in a buttress dam constructed about 60 years ago. Its layout is shown in Figure 1. The maximum structural height of the dam is $39 \mathrm{~m}$. The outlet, equipped with a segment gate followed by a short conduit, runs through the dam body. It was originally designed for flood discharge during the construction period, implying that it only experienced flood discharges at low reservoir levels. Since the first impounding of the reservoir, it has never been operated. Figure 2 shows the outlet seen from the downstream side with a low tailwater level.

In light of the dam-safety guidelines, many existing highhazard dams in Sweden need to be refurbished to meet the updated safety requirements, as is also the case for the dam in question. To, for example, rehabilitate the dam, the reservoir level needs to be lowered. As the threshold of the surface spillway is situated high, to use the bottom outlet becomes the only possibility of further drawing down the reservoir and emptying it if needed for foundation treatment. This implies that the segment gate would operate at higher reservoir water level than during the dam construction time.

If the outlet operates at high reservoir levels, the need for air supply to the high velocity flow would increase 
TABLE 1: Air entrainment formulas for steady hydraulic jump.

\begin{tabular}{lccc}
\hline Reference & Pipe shape & $m$ & $n$ \\
\hline Kalinske \& Bliss [2] & Circular & 0.0066 & 1.40 \\
Ahmed et al. [11] & Circular & 0.040 & 0.85 \\
Escarameia et al. [12] & Circular & 0.0025 & 1.80 \\
Rajaratnam [13] & Rectangular & 0.018 & 1.245 \\
Wisner et al. [14] & Rectangular & 0.014 & 1.40 \\
Rabben et al. [15] & Rectangular & 0.030 & 0.76 \\
\hline
\end{tabular}

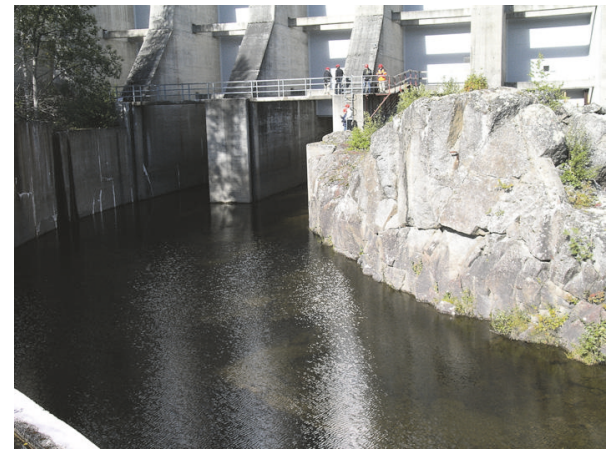

Figure 2: The bottom outlet seen from downstream, at a low tailwater stage.

significantly. As the air supply vent in the roof of the gate chamber is limited in size, there is a need to assess if it should be enlarged to reduce its throttling effect on the air flow. Another fact is that, depending on the tailwater water stage, the flow state in the conduit would be different. If the water stage is low or the river course downstream is dry, free outflow would occur. If it is conduit is initially submerged, a forced hydraulic jump would develop in the conduit when the gate gradually opens. Many outlets in Sweden have a similar layout and flow conditions. As an inherent phenomenon of the outlets, exploration of transient behaviors of the water-air flow is essential. The issue of cavitation associated with high velocity flows is not the concern of the study.

\section{Numerical Model Set-Up}

4.1. Geometrical Layout. The longitudinal profile of the bottom outlet is illustrated in Figure 3. The concrete-lined outlet is horizontal from upstream to downstream, with the floor elevation $+236.0 \mathrm{~m}$. The full reservoir water level is at $+273.0 \mathrm{~m}$. In the reservoir, the intake follows the sloping face of the buttress dam. The conduit is rectangular in cross section, with a constant width of $5.5 \mathrm{~m}$ throughout the waterway. The radial gate has the same width, $B=5.5 \mathrm{~m}$; its full opening height is $h_{0}=3.65 \mathrm{~m}$.

Downstream of the gate, the height of the gate chamber is $8.65 \mathrm{~m}$. The air supply to the flow is via an air vent in the roof of the chamber. The trunnion girder of the gate that accommodates the trunnion pin is $2.5 \mathrm{~m}$ long in the flow direction. Its lower edge has the elevation $+239.65 \mathrm{~m}$, implying that the flow passage here has the same height as $h_{0}$. The conduit downstream of the girder has a height of $6.8 \mathrm{~m}$

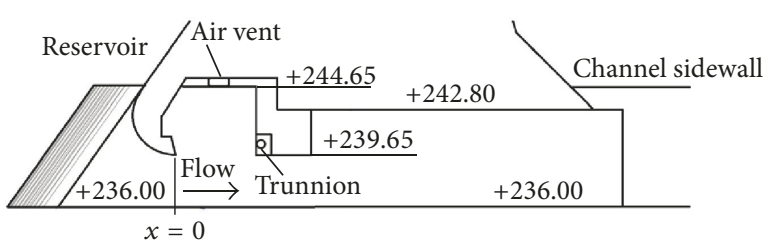

FIGURE 3: Longitudinal profile of the bottom outlet in the buttress dam.

TABLE 2: Typical opening speeds of radial gates in Sweden.

\begin{tabular}{lcc}
\hline Drive system & Power supply & Opening speed $(\mathrm{m} / \mathrm{min})$ \\
\hline \multirow{2}{*}{ Chain hoist } & DC & $0.15-0.2$ \\
\multirow{3}{*}{ Wire rope hoist } & AC & $0.5-0.6$ \\
& DC & $0.6-0.7$ \\
& AC & $0.7-1.0$ \\
\hline
\end{tabular}

and a length of $21.5 \mathrm{~m}$. Counted from the gate position at $x=$ 0 , the girder centerline and the lower end of the conduit are at a distance of 6.75 and $29.6 \mathrm{~m}$, respectively.

4.2. Opening Speed of Radial Gate. A gate drive system is usually of type mechanical hoist or hydraulic cylinders [26]. In the existing bottom outlets, wire rope hoist and chain hoist are the common methods to operate the gates. Older facilities are often equipped with a chain-drive system. The power supply can be either alternating current (AC) or direct current (DC). According to plant operation manuals, typical opening speeds of radial gates in the outlets in Sweden are summarized in Table 2.

The gate opening speed is dependent upon the drive system and power supply to it. The wire rope hoist operates faster than the chain hoist and AC faster than DC. It is unusual to open a segment gate at a speed over $1 \mathrm{~m} / \mathrm{min}$. For the outlet in question, the radial gate is lifted with wire rope hoist and AC after refurbishment. Its opening speed is set at $1.52 \mathrm{~cm} / \mathrm{s}(0.0029 \mathrm{rad} / \mathrm{s})$, implying that it takes $t_{0}=240 \mathrm{~s}$ to fully open the gate.

4.3. Grid Generation. The reservoir length and width included in the model are 100 and $80 \mathrm{~m}$, respectively. Downstream of the conduit, the area is an open channel, with a length of $15 \mathrm{~m}$ included. The geometry and grid in 3D are generated in ANSYS DesignModeler [27]. Several grids of varying cell sizes are tested to ensure grid-independent solutions. 


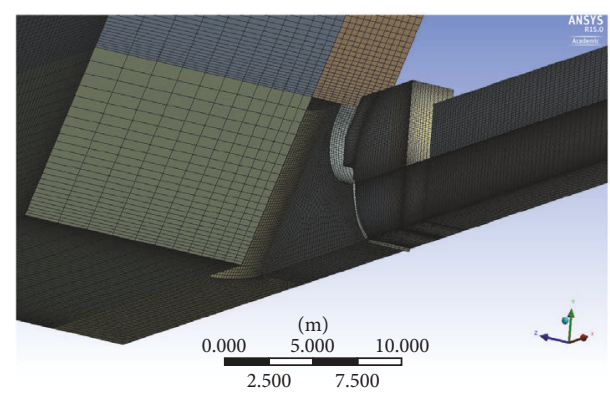

(a)

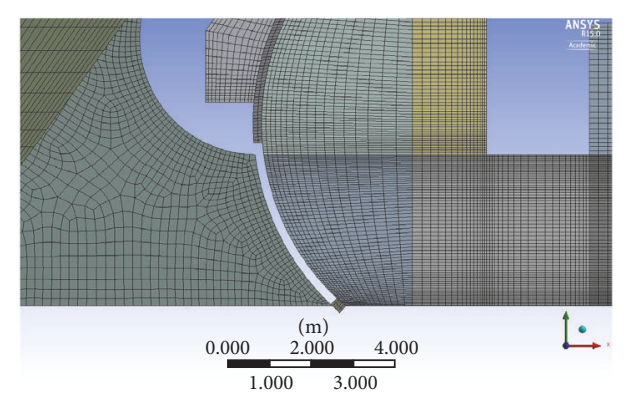

(b)

FIgURE 4: Numerical grid. (a) An overall view; (b) locally at the radial gate, with the gate at the closed position.

Due to the long CPU time of the transient simulations, grid independence is checked for three grids through steady-state calculations. When a coarse grid is refined, the refinement is made both globally and locally. A larger grid density is given to the gate area and the conduit. The computational domain is finally discretized into 680,000 hexahedral elements; the number of nodes is 730,000 . Figure 4 shows the grid.

4.4. Adaptive Mesh following Gate Movement. The lower edge of the radial gate and its skin plate are mapped as in the prototype. The gate is given a constant thickness of $30 \mathrm{~cm}$. The steel structure behind the gate with horizontal girders, lateral bracings, and trusses are disregarded as they do not affect the water flow; their effect on the air flow is negligible. To avoid an extra degree of difficulty to the modelling, the strut arms of the gate are excluded.

User Defined Function (UDF) in FLUENT makes it possible to generate time-dependent moving adaptive meshes to account for the radial gate movement. A layering method is activated for the dynamic zone, in which the updated mesh follows the outer configuration of the gate when the gate moves a time step forward. Efforts are made to obtain a decent quality mesh at the gate. The gate opens from the closed position to its full opening.

4.5. Two-Phase Flow Model. The two-phase water-air flow in the bottom outlet is modelled with the finite-volume solver FLUENT, in which the Volume of Fluid (VOF) is used in combination with the RNG $k-\varepsilon$ turbulence models [28]. The water-air phases share a single common set of mass conservation and momentum equations; the VOF is tracked for each phase in a computational cell. No mathematical formulations of the VOF model are given here; more descriptions can be found in, for example, Ho et al. [29], Chatila and Tabbara [30], Liu and Yang [31], and Satrapa et al. [32].

4.6. Boundary Conditions. With the geometrical symmetry, only half of the outlet is modelled. The hydrostatic water pressure applies to the upstream reservoir boundary, implemented also with a UDF. The reservoir water surface is directly covered with a horizontal wall and treated as a slip boundary for the water. The air supply vent in the gate chamber acts as a pressure inlet with the atmospheric pressure. For the downstream end, an outflow condition applies if water discharges freely; hydrostatic water pressure applies if a known water stage is preset. Simulations are performed for both the free and submerged discharges.

4.7. Convergence and CPU Time. Parallel computations are performed on a mainframe computer, using one node with double quad-core AMD Opteron $2.2 \mathrm{GHz}$ CPU (2374 HE) and $16 \mathrm{~GB}$ memory. Owing to its quicker convergence than the explicit one, the implicit discretization scheme applies. The time step is $0.001-0.002 \mathrm{~s}$ governed by the Courant number. The residual values of mass, velocity, and volume fraction are the convergence criterion. For each time step of a time-dependent solution, the calculations converge if the scaled residuals of the variables are lowered by approximately three orders of magnitude. The typical CPU time of a moving gate simulation is approximately two weeks if the outlet discharge is free and eight (8) months if the discharge is submerged downstream. The latter takes surprisingly longer CPU time than the former.

\section{Physical Model Tests}

In connection with the rehabilitation of the dam, hydraulic model tests were performed to evaluate related hydraulic issues of the bottom outlet, including downstream channel modifications for effective energy dissipation. Figure 5 shows the up- and downstream view of the outlet in the model. The model was based on the Froude law of gravity, with a scale of $1: 50$. Sufficiently large areas were included both upand downstream to reasonably reproduce the approach flow to the outlet and the tailwater [33-35]. The bottom outlet was made in plexiglass plates to keep manufacture errors as little as possible. Point gauges were used to read water levels. Two types of manometers were installed to monitor water and air pressures, respectively. The flow rate in the model was measured with a calibrated magnetic flow meter, with a relative error below $\pm 1 \%$.

For either CFD simulations or physical model tests of a bottom outlet, the issues of concern include outlet discharge capacity and air demand. Examination of the discharge capacity is an essential parameter to be determined and it refers to the relationship between water head acting on the 


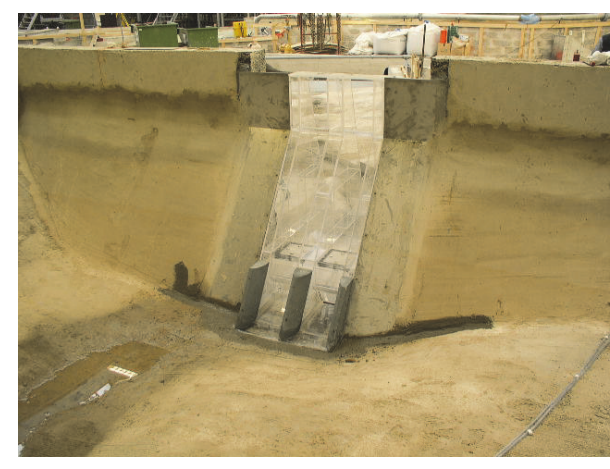

(a)

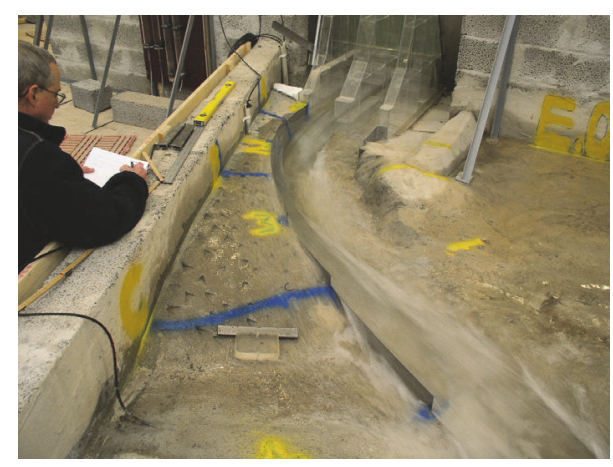

(b)

FIgUre 5: Physical hydraulic model of the bottom outlet. (a) Upstream view; (b) downstream view with free outflow.

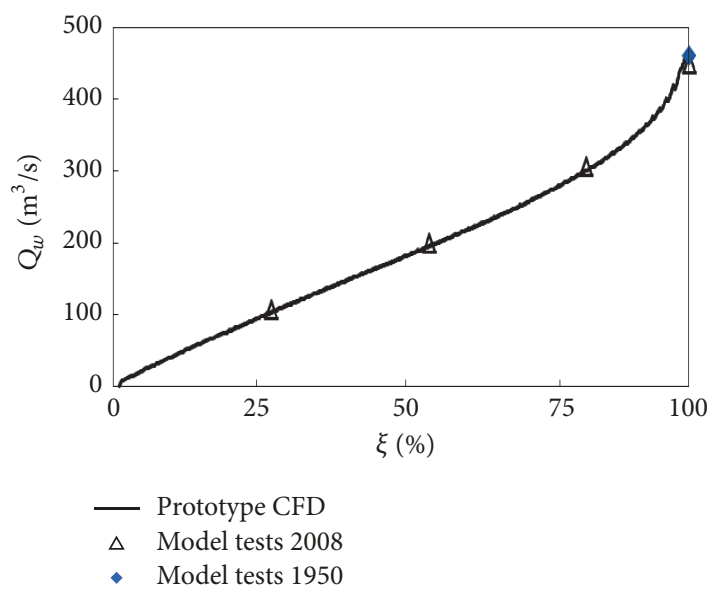

(a)

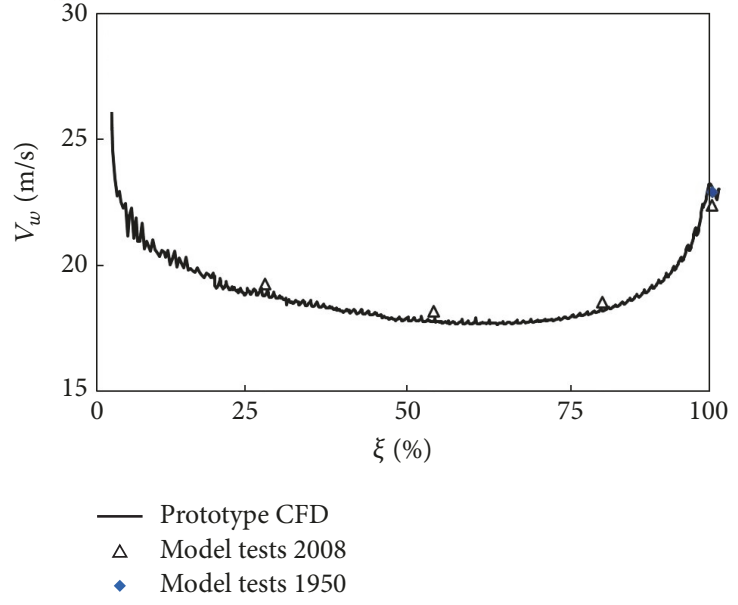

(b)

Figure 6: Comparisons between CFD and experiments, $Q_{w}$ and $V_{w}$ as function of $\xi$.

gate and flow discharge. As air flow in the model does not follow the Froude law and cannot be directly converted to the prototype, CFD modelling plays a unique role in estimations of the air flow rate.

\section{Free Outlet Flow}

If the downstream water level is low or the river bed is dry, free outlet discharge occurs. The CFD simulations are made at the full reservoir water level, resulting in the discharge capacity at several fixed gate positions.

6.1. Outlet Discharge. Figure 6 shows the results of $Q_{w}$ and $V_{w}$ as a function of the dimensionless gate opening $\xi$, which is defined as the ratio of $h_{g}$ to $h_{0}$. Here $V_{w}$ refers to the mean outflow velocity under the gate and $h_{g}$ to the time-dependent opening of the gate, measured as the vertical distance from the conduit bottom to its lower edge. Comparisons are made with the experimental results from 2008 and even from 1950 before the dam was constructed. For the 2008 tests, the result corresponds to fixed gate positions at $h_{g}=1.0,2.0,3.0$, and $3.65 \mathrm{~m}$; for the 1950 tests, it refers to $h_{g}=3.65 \mathrm{~m}$. Table 3 lists the $\eta$ values of the 2018 results, in which $\eta$ denotes the
TABLE 3: Comparison of the $Q_{w}$ results between the 2008 model tests and CFD.

\begin{tabular}{lcccc}
\hline$h_{g}(\mathrm{~m})$ & 1.0 & 2.0 & 3.0 & 3.65 \\
Test results $\left(\mathrm{m}^{3} / \mathrm{s}\right)$ & 106 & 200 & 306 & 449 \\
CFD results $\left(\mathrm{m}^{3} / \mathrm{s}\right)$ & 108 & 203 & 310 & 435 \\
$\eta(\%)$ & -1.9 & -1.5 & -1.0 & +3.1 \\
\hline
\end{tabular}

relative error in $Q_{w}$ : that is, $\eta=\left(Q_{w \text {,test }}-Q_{w, \text { CFD }}\right) / Q_{w \text {,test }}$. The relative discrepancy in the discharges between the CFD and the model tests is below 3.1\%.

The value of $V_{w}$ decreases rapidly in the beginning of the gate opening, up to $\xi \approx 8.2 \%$. Then it changes gradually to a plateau of $17-17.5 \mathrm{~m} / \mathrm{s}$ within $\xi \approx 41-82 \%$. Towards the full gate opening, $V_{w}$ increases again. Higher flow velocity indicates lower local headlosses at the gate and accordingly larger discharge coefficient. The results show good agreement between the CFD modelling and experiments.

6.2. Air Demand. Air supply to the gate chamber and further to the flow is via the air vent in the floor of the machine room. 


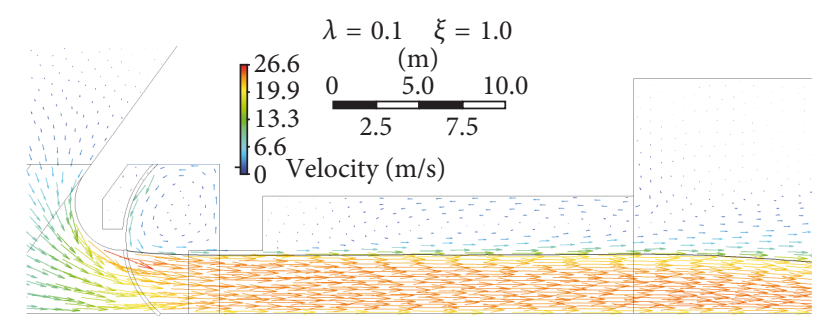

FIGURE 7: Steady-state air-water flow field at the full gate opening $(\lambda$ $=0.1, \xi=100 \%)$.

Air also enters the conduit from its downstream end. The size of the vent, denoted as $A\left(\mathrm{~m}^{2}\right)$, is an issue of concern as it governs the air flow into the outlet. For this purpose, simulations are performed with five options, $A=0,2,10,20$, and $30 \mathrm{~m}^{2}$, that is, from a closed vent to an unrealistically large one. A nondimensionalised vent parameter $\lambda=A /(B$. $h_{0}$ ) is defined; their corresponding values are $\lambda=0,0.1,0.5$, 1.0 , and 1.5 .

The simulations indicate that there is always air supply from the downstream end into the conduit. The situation differs from that in a long tunnel where the air movement always follows the water flow [3]. As air moves with the water at the water surface, a large anticlockwise air flow circulation exists in the conduit, irrespective of the vent options. When the gate is fully open $(\xi=100 \%)$, limited space is left as air passage under the trunnion girder. Accounted from $\mathrm{VOF}=$ 0.5 , the passage is merely $30 \mathrm{~cm}$. If $\lambda=0$, air moves against the outflow direction, at a maximum velocity of $8.5 \mathrm{~m} / \mathrm{s}$; the air pressure drop in the gate chamber fluctuates between 3 and $4 \mathrm{~m} \mathrm{H}_{2} \mathrm{O}$, which is significant. Already at $\lambda=0.1$, the situation is improved, giving rise to streamwise air flow below the girder and the chamber pressure drop becomes small. Figure 7 shows its flow velocity field of both the water and air at $\xi=100 \%$. A counterclockwise air flow circulation occurs also in the gate chamber. Vahdati [36] performed also CFD modelling of the bottom outlet. Though his focus was placed on the water flow, the air flow pattern agrees well with the present study.

Figure 8 shows the results of $\beta$ and $V_{a}$ as a function of $\xi$. $V_{a}$ denotes the mean air flow velocity through the vent. For all vent options, $\beta$ increases rapidly immediately after the opening of the gate. Obviously, the three larger $\lambda$ values lead to a few times higher $\beta$ than $\lambda=0.1$. As the gate gradually opens, $\beta$ increases slowly with $\xi$. Towards the end of the gate movement, $\beta$ drops and $V_{a}$ approaches $18-20 \mathrm{~m}^{3} / \mathrm{s}$, which is almost independent of the vent size. A short while after the full opening, both the water and air flows fluctuate somewhat, but the magnitudes are small. The variation of $V_{a}$ as a function of $\xi$ follows the pattern of $\beta$. The vent $\lambda=0.1$ gives rise to moderately higher $V_{a}$ values, with $V_{a} \approx 10 \mathrm{~m} / \mathrm{s}$ at the full opening. For $\lambda \geq 0.5, V_{a}$ varies insufficiently with $\xi ; V_{a}$ varies only between 0.7 and $2 \mathrm{~m} / \mathrm{s}$.

In a Froude law model, the air pressure drop cannot be correctly modelled. However, its trend of change with the gate opening is qualitatively consistent with the measurements by the manometers in the physical model [33].

\section{Submerged Outlet Flow}

If the tailwater stage is higher than the roof elevation of the outlet conduit, which is due to the flood release from the surface spillway, the outflow becomes then submerged. The conduit roof elevation is $+242.80 \mathrm{~m}$. Simulations are made at a tailwater stage of $1.0 \mathrm{~m}$ above the roof; the resulting downstream water depth is $h_{2}=7.8 \mathrm{~m}$. This means that when the gate starts to open, the same water depth acts on its downstream skin plate. The air vent is set sufficiently large with $\lambda=1.5$, so that it does not throttle the air flow.

7.1. Formation of Hydraulic Jump. Figure 9 shows the variation of the water depth $(H)$ in the gate chamber with $\xi$. The water downstream of the radial gate stands still before the gate opens, with $H=h_{2}=7.8 \mathrm{~m}$. Due to this, $H$ rises by approximately $0.35 \mathrm{~m}$ at $\xi=2.2 \%$. With the water in the conduit starting to move downstream, $H$ drops quickly by $1.4 \mathrm{~m}$ to $H=6.75 \mathrm{~m}$ at $\xi=4.7 \%$, which is closely related to the chamber cross-sectional area. It then recovers to $H=7.65 \mathrm{~m}$ at $\xi=8.8 \%$ before slowly descending. As time progresses, $H$ shows a moderately quick decrement at $\xi=35.6 \%$.

Figure 10 illustrates, along the middle of the outlet, a sequential change of the instantaneous air-water flow patterns as the gate opens from its closed position to its full opening, plotted by VOF and flow velocity vector. The gate opening intervals between two neighboring snapshots are not constant but reflect the typical instants during the gate movement. The flow is strongly unsteady and variable. Even a $1 \%$ change in $\xi$ (time interval 2.4 s) gives rise to two somewhat dramatically different structures of flow, especially within $\xi=$ $50-85 \%$.

During the early stage of the gate opening and up to $\xi \approx 38 \%$, the gate chamber is filled with water. The small gate openings result in a jet flow along the conduit bottom, with a jet thickness that increases in the flow direction for a given gate opening. At $\xi=34 \%$, an anticlockwise vortex tends to build up downstream of the girder. Before $\xi \approx 38 \%$, the change in the flow pattern is relatively small, with limited water motions above the jet flow. Approximately at $\xi=40 \%$, $H$ drops below the lower edge elevation of the trunnion girder and air gets then entrained into the conduit downstream. The jet flow generates now two anticlockwise vortices in the conduit, with the downstream one somewhat large than the upstream one. Up to this gate opening, the outflow can be paralleled with the plane turbulent wall jet seen in the literature, featuring high velocity and a fixed outflow height submerged in tailwater [37]. The distinctive feature here is that, due to the upward gate movement, the conduit flow can hardly adapt itself to the enlarging jet outflow and reach an equilibrium. As a result, hysteretic effects do exist in the flow.

At $\xi \approx 42.5 \%$, some water above the jet reverses its direction and hits the gate. The bottom current leads to a large zone of water circulation, with large air pockets trapped in the middle. The circulation zone occupies almost the whole space above the jet. At $\xi \approx 45 \%$, the outflow jet becomes strong enough to push the water downstream and away from the gate. As a result, more air enters the conduit and a hydraulic jump takes form, with $h_{1}=1.20 \mathrm{~m}$ and $V_{1}=24.8 \mathrm{~m} / \mathrm{s}$, 


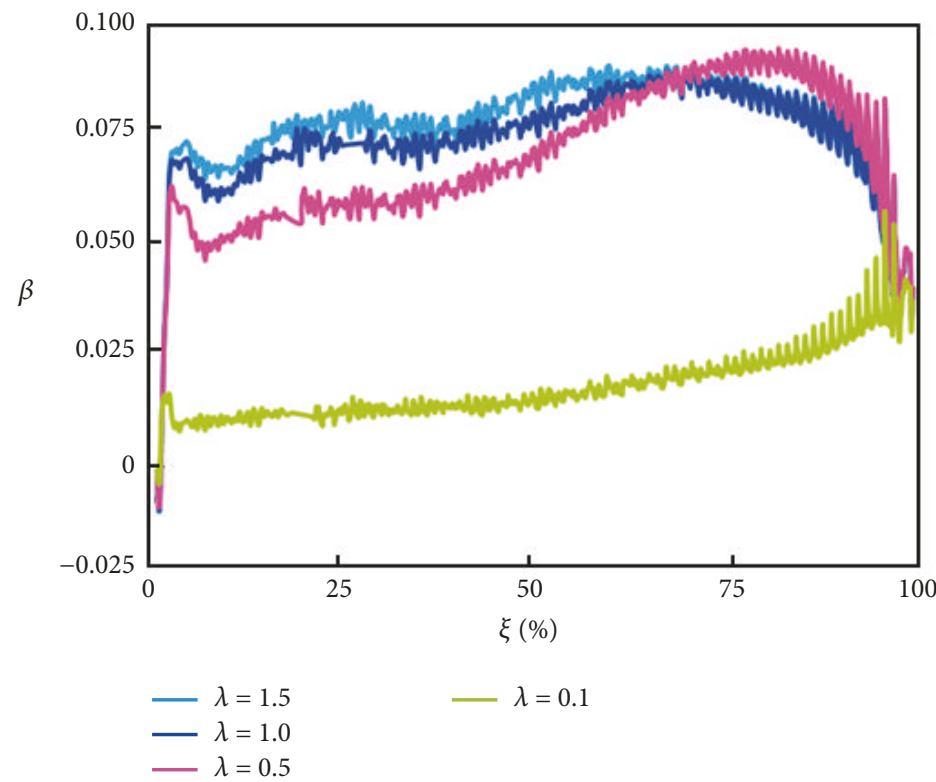

(a)

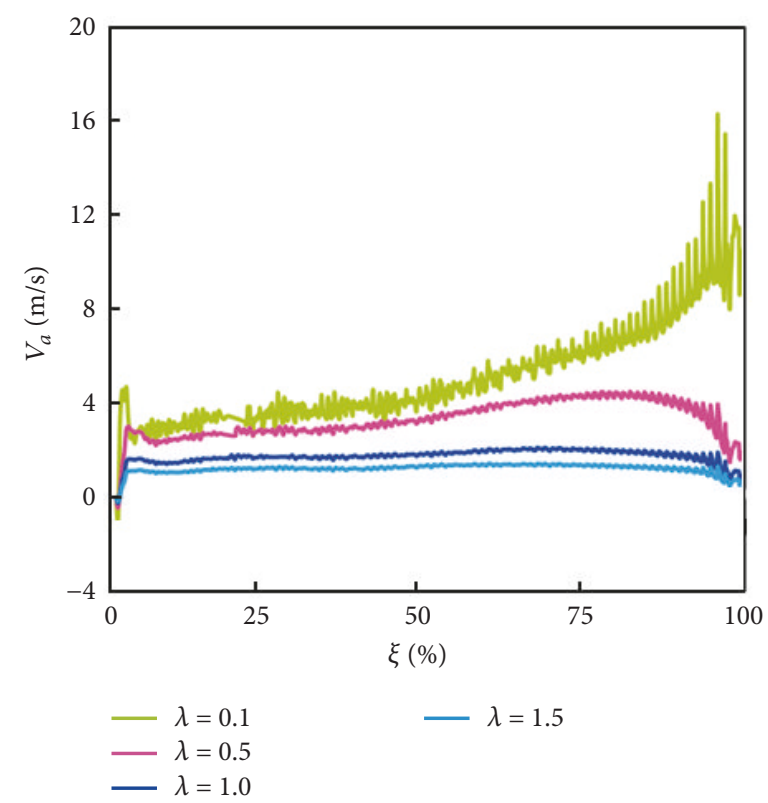

(b)

Figure 8: Change of $\beta$ and $V_{a}$ with $\xi$ at $\lambda=0.1,0.5,1.0$, and 1.5 .

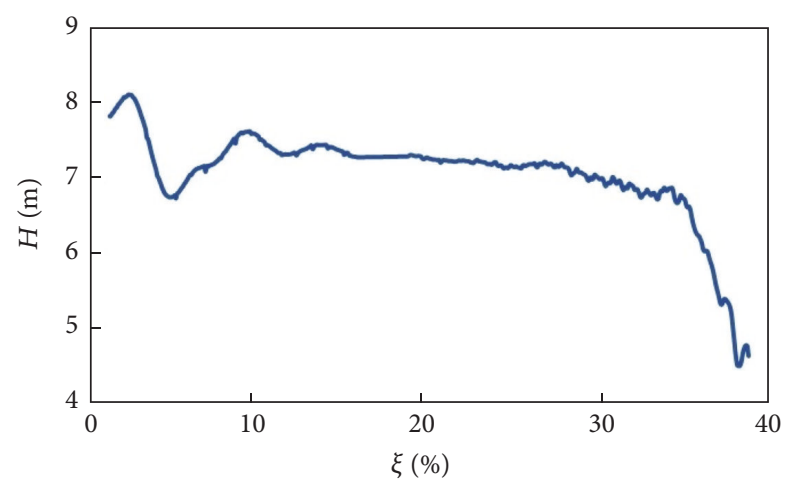

FIGURE 9: Change of $H$ with $\xi$.

corresponding to $F=7.23$. Afterwards, strong turbulent mixing and overlapping of water columns with air pockets occur in the conduit.

At $\xi \approx 48 \%$, the hydraulic jump moves further downstream and the major part of the conduit is filled with air. At $\xi \approx 55 \%$, a considerable amount of air is trapped in the conduit and transported downstream. The flow features an overturning water nappe from below the girder that hits against both the gate and the chamber roof. In the formation of a conventional hydraulic jump from a submerged wall jet, the transition is usually represented with a sequence of steady-state flow stages and the tailwater is with free surface [37-39]. The flow with free surface easily adjusts itself to pressure fluctuations imposed by the jet. In our case, the tailwater elevation is $1.0 \mathrm{~m}$ above the conduit roof and the flow is constantly pressurized. This means that the resistance to the jet is stronger. Together with the hysteretic effects, this gives rise to the reversed water movements above the jet.
At $\xi \approx 61.5 \%$, the strong jet pushes the water back into the conduit, resulting in strong mixing and large air pockets in the water. Surface roller waves travel also back and forth on the jet. As the gate continues to open (as at $\xi \approx 68 \%$, $75 \%$, and $82 \%$ ), the trapped air forms large air pockets under the conduit roof, some of which also break up, become coalescent, and follow the stream.

When $\xi>90 \%$, a large air cavity forms in the conduit, communicating with the gate chamber via the narrow air passage below the girder. The passage becomes smaller as the gate moves upwards but remains. When the gate approaches its full opening, the location of the resulting hydraulic jump is relatively stable. At $\xi=100 \%, h_{1}=3.35 \mathrm{~m}, V_{1}=24.3 \mathrm{~m} / \mathrm{s}$, and $F=4.23$. The supercritical outflow extends beyond the trunnion girder and into the conduit, with roller waves and air pockets in the conduit.

7.2. Outflow Discharge. In physical model tests, flow discharges are all measured under steady-state conditions; it is difficult to control and measure transient discharges following a moving gate. One often resorts to CFD modelling to find the answer. During the gate opening, Figure 11 compares the $Q_{w}$ results between the free and submerged outflows with the hydraulic jump. The variable $\alpha$ refers to the difference between them divided by the free outflow discharge.

It is discernable that the initial outflow at the gate is submerged; as a result, the discharge capacity is affected. Obviously, the largest difference, up to $23 \%$, occurs at the very beginning of the gate movement. With an increasing gate opening, the water is pushed away and the difference becomes smaller. Roughly after $\xi \approx 45 \%\left(h_{g} \approx 1.65 \mathrm{~m}\right)$, the outflow becomes "free." Still, due to the overturning water nappe and roller waves, the subsequent discharge is slightly affected, resulting in some minor perturbations. 


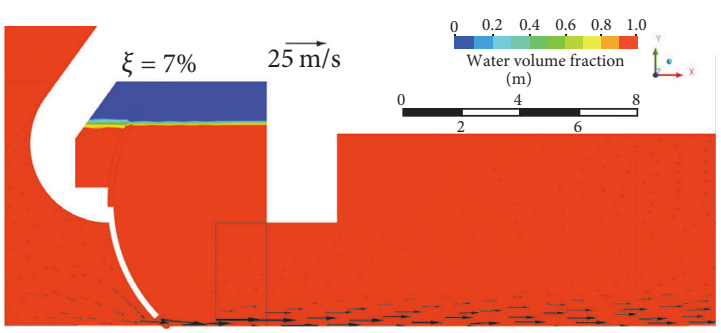

(a)

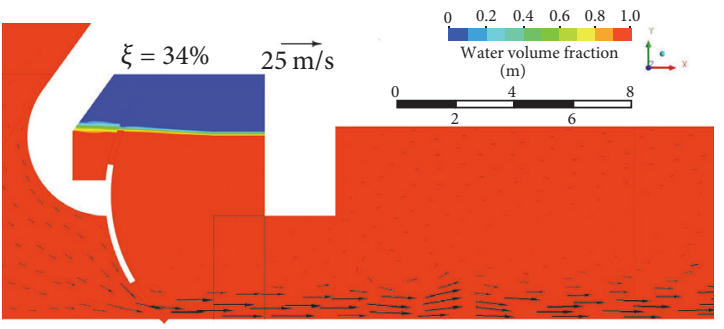

(c)

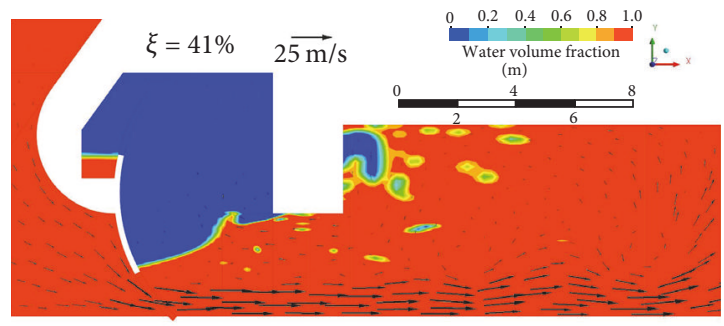

(e)

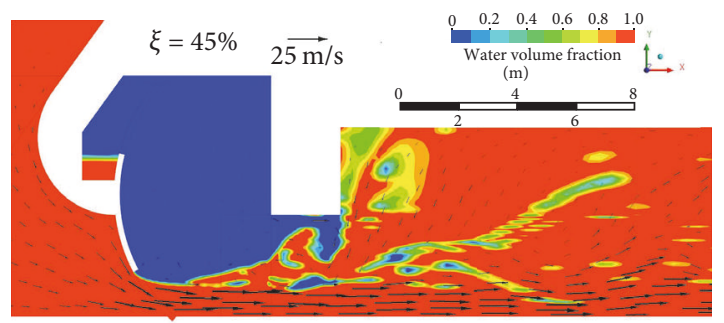

(g)

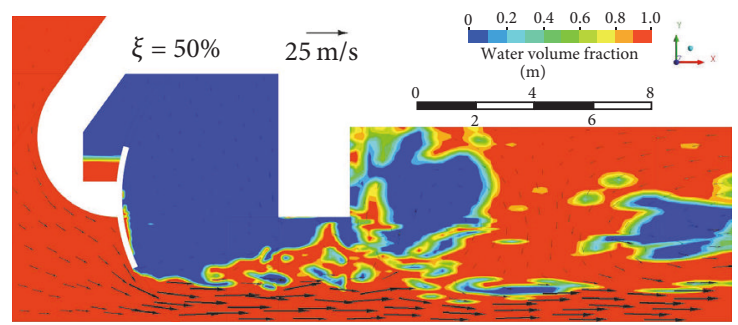

(i)

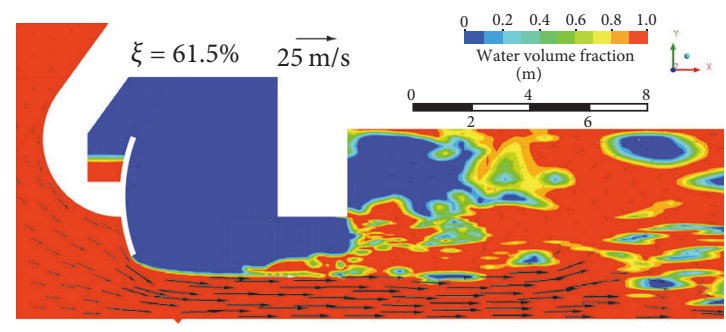

(k)

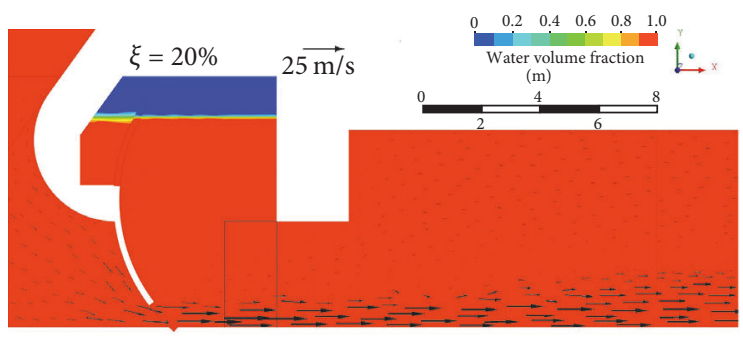

(b)

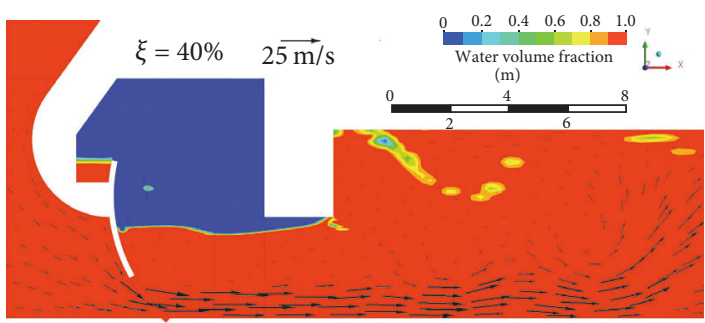

(d)

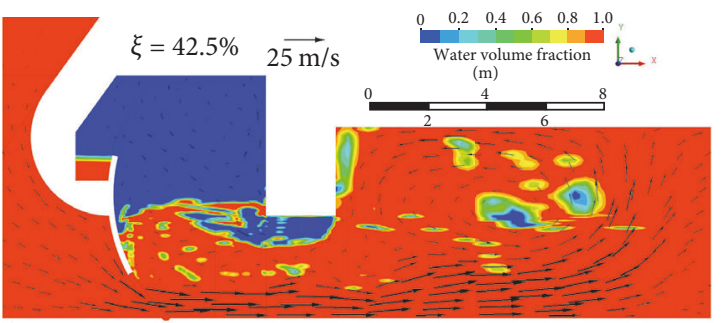

(f)

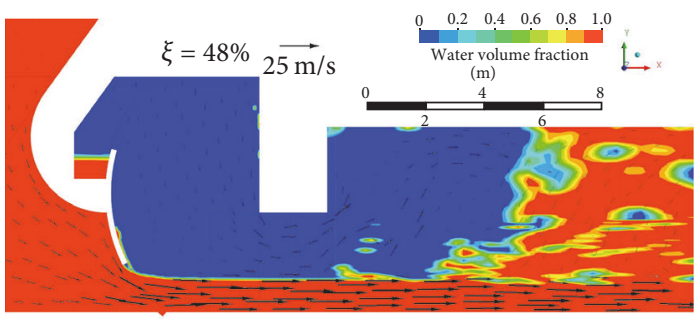

(h)

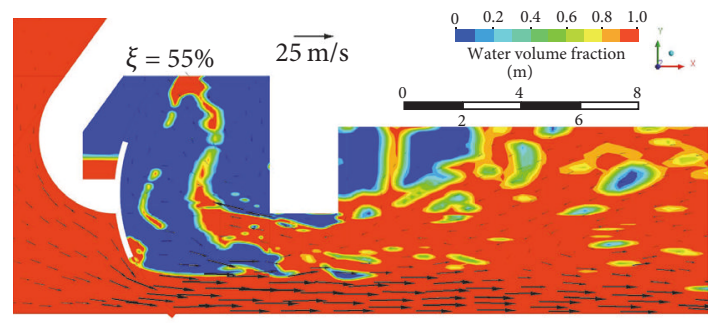

(j)

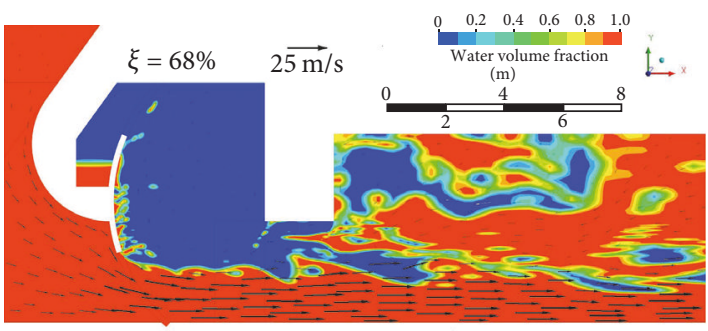

(1)

FIgUre 10: Continued. 


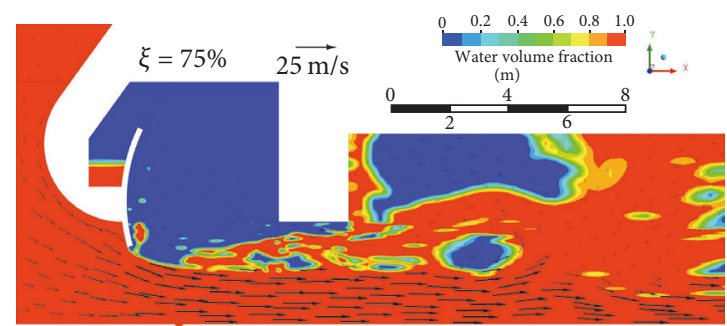

(m)

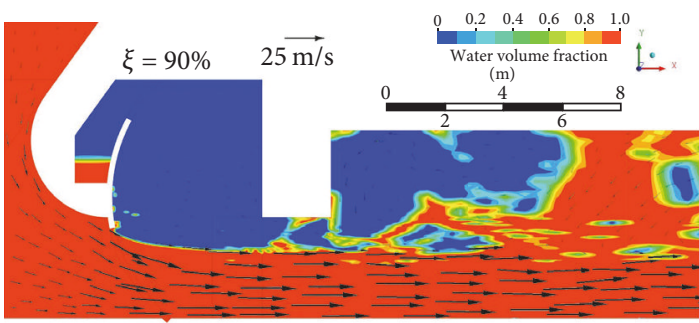

(o)

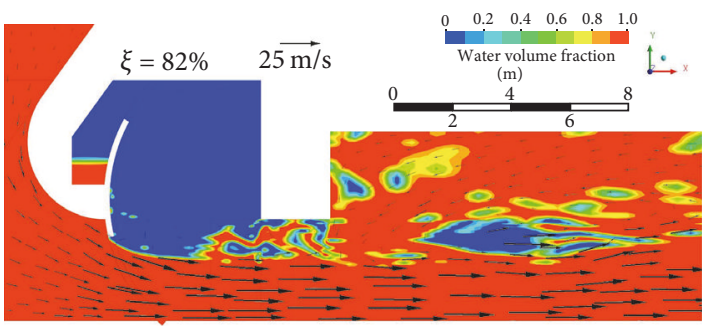

(n)

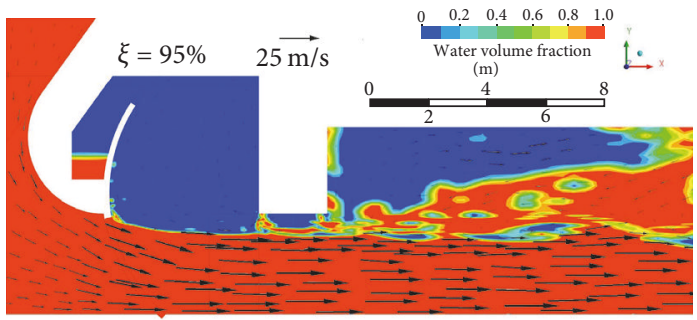

(p)

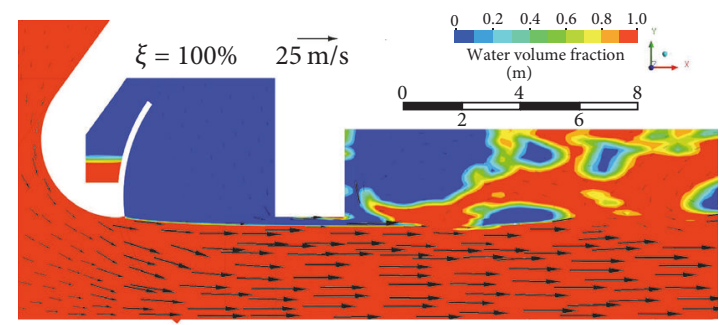

(q)

Figure 10: Sequential snapshots of the submerged outflow from the radial gate from $\xi=7$ to $100 \%$. The instantaneous patterns are colored by VOF and the velocity field is illustrated by velocity vectors.

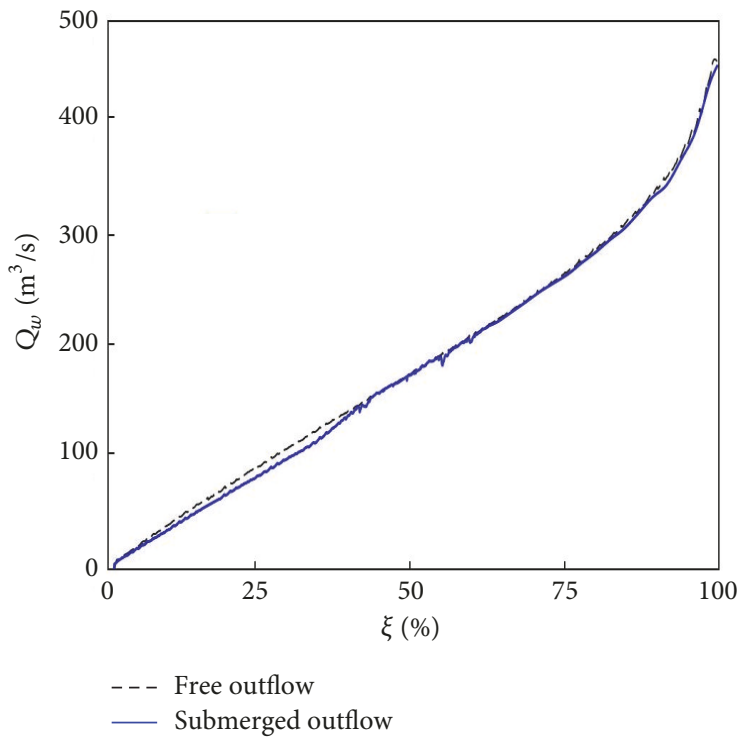

(a)

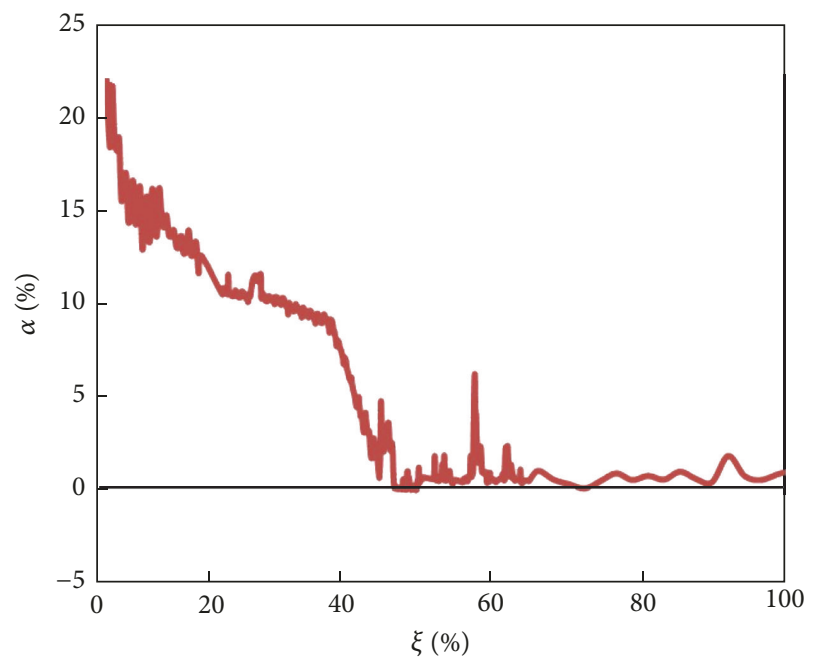

(b)

FIgURE 11: Differences between free and submerged outflow, $Q_{w}$ and $\alpha$ as a function of $\xi$. 


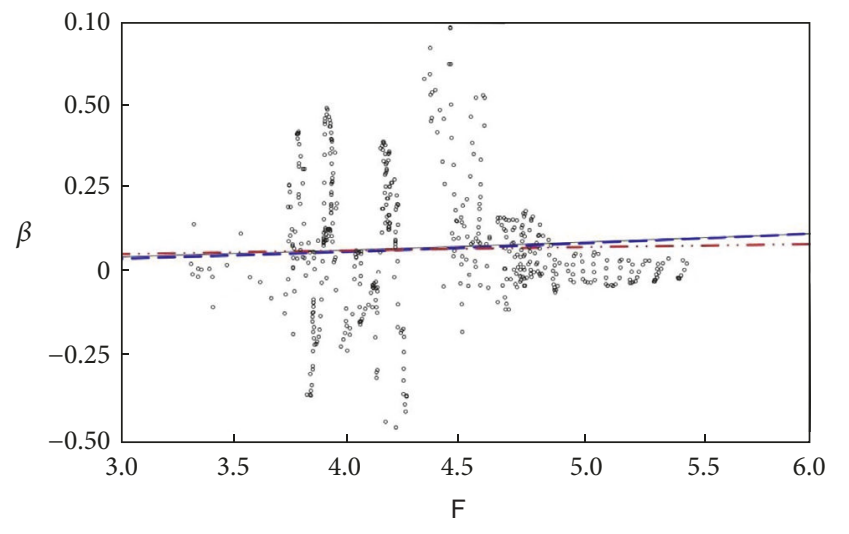

$\begin{array}{lll}\text { _ Rajaratnam (1967) } & \ldots-. \cdot \text { Rabben et al. (1983) } \\ \text { - - - Wisner et al. (1975) } \quad \therefore \quad \beta\end{array}$

Figure 12: The change of $\beta$ as function of $F$.

7.3. Transient Air Demand. As shown in Table 1, the formulas by Rajaratnam [13], Wisner et al. [14], and Rabben et al. [15] are usually adopted to estimate air demand in the formation of steady-state hydraulic jumps in rectangular channels. Figure 12 illustrates, during the gate opening, the change of $\beta$ as a function of $\mathrm{F}$. The air demand predicted by the three formulas is also included in the diagram.

Following the opening of the gate, that is, with the increase of $\xi, F$ becomes smaller. During the formation of the hydraulic jump, air moves, through the air vent, both in and out of the gate chamber. The air supply can be a few times higher than estimated by the formulas, which is partially attributable to the intensive air entrainment and the overlapping and collisions of defragmented water columns in the enclosed conduit. Towards the end of the gate movement, the position of the resulting hydraulic jump is relatively stable. The air demand becomes also more or less constant and is in line with the results from the formulas.

\section{Conclusions}

In a bottom outlet, it is essential to understand, in the course of its gate opening, the transient features of the air-water flow and air demand so as to avoid unexpected consequences. In conjunction with the rehabilitation of an outlet, CFD simulations of the gated outflows are performed as a complement to physical model tests. The radial gate is hoisted with wire ropes and AC power supply after refurbishment. It opens at a constant speed, for which an adaptive mesh is generated to follow the gate movement. The purpose of the simulations is to examine the transient features of the flow at both free and submerged discharges and assess the air demands. With the study, the following conclusions are drawn.

For the free outlet discharge, the CFD modelling is made at the full reservoir water level. The resulting discharge capacity at several gate positions is conformable to the experimental results, with a maximum discrepancy below $+3.1 \%$. The outflow exhibits higher flow velocity in both small and large gate openings, indicating lower local headlosses and accordingly higher discharge coefficients.
A few options of the air vent size are simulated. Air always enters the conduit from its downstream end, resulting in an air flow circulation above the water in the conduit. If the air vent is sealed, significant air pressure drop would occur in the gate chamber at the end of the gate opening. A larger vent area than $10 \mathrm{~m}^{2}$ leads to similar air flow behaviors and a few times higher air supply rate than $2 \mathrm{~m}^{2}$ during the gate opening. The chamber air pressure drop becomes also insignificantly small.

For the submerged outflow, the discharge under the gate is reduced by the tailwater and slightly by the flow during the formation of the hydraulic jump. Compared to the free outflow, the maximum reduction is about $23 \%$ in the very beginning of the gate rise. Approximately at $45 \%$ of the full opening, the gate outflow becomes "free" and strong enough to push the downstream water away from the gate, marking the beginning of the hydraulic jump formation. The subsequent flow features strong turbulence mixing and roller waves travelling on the flow jet. At the 55\% opening, the overturning water nappe hits against both the gate and chamber roof. With the gate moves further upwards, large air pockets build up and then break up in the enclosed conduit, giving rise to collisions of defragmented water bodies. With approach to the full gate opening, the location of the hydraulic jump becomes relatively stable. The outflow jet extends beyond the trunnion girder, with formation of a large air cavity in the conduit. The cavity is connected with the gate chamber via the narrow air passage below the girder.

During the gate movement, the formation of the submerged hydraulic jump is strongly turbulent and unsteady in the flow direction. As a result, air flows both into and out of the gate chamber. The process leads to a few times more air flow rate than that in a steady hydraulic jump with free surface.

\section{Notations}

A: Air vent area

$B$ : Radial gate width

F: Froude number

g: Acceleration of gravity

$H$ : Water depth in the gate chamber

$h_{0}$ : Full opening height of the gate

$h_{1}$ : Water depth upstream of hydraulic jump

$h_{2}$ : Water depth downstream of hydraulic jump

$h_{g}$ : Time-dependent gate opening

$m$ : Constant

n: Constant

$Q_{a}:$ Air flow discharge in the air vent

$Q_{w}$ : Water flow discharge at the gate

$V_{1}$ : Mean flow velocity upstream of hydraulic jump

$V_{a}$ : Mean air flow velocity in the air vent

$V_{w}$ : Mean flow velocity under the gate

$\alpha$ : $\quad$ Relative difference of gate discharge

$\beta$ : $\quad$ Ratio of air flow to water flow discharge

$\lambda$ : Dimensionless vent area

$\xi$ : Dimensionless gate opening

$\eta$ : $\quad$ Relative discharge error. 


\section{Conflicts of Interest}

No potential conflicts of interest were reported by the authors.

\section{Acknowledgments}

The study is a research project within hydraulic design cofunded by the Swedish Hydropower Centre (SVC), Vattenfall AB, and the 111 Project. SVC is established by the Swedish Energy Agency, Energiforsk AB, and Swedish National Grid, together with Royal Institute of Technology (KTH), Luleå University of Technology (LTU), Chalmers University of Technology (CTH), and Uppsala University (UU). The 1st and 3rd authors are members of the 111 Project granted by Ministry of Education and State Administration of Foreign Experts Affairs, China (Grant no. B17015), with the State Key Laboratory of Hydrology-Water Resources and Hydraulic Engineering, Hohai University, as executive organization.

\section{References}

[1] J. Dath and M. Mathiesen, "Pre-studies of hydraulic design: inventory and general evaluations of bottom outlets in Swedish dams," Elforsk Report no. 10:87, Stockholm, Sweden, 2007.

[2] A. A. Kalinske and P. H. Bliss, "Removal of air from pipelines by flowing water," ASCE Journal of Hydraulic Division, vol. 13, no. HY10, pp. 480-482, 1943.

[3] H. T. Falvey, Air-water flow in hydraulic structures, United States Department of the Interior, Water and Power Resources Service, Engineering Monograph No. 41, Denver, Colo, USA, 1980.

[4] H. Kobus, "Introduction to air-water flows," in Air Entrainment in Free-Surface Flows, Balkema, Rotterdam, Netherlands, 1991.

[5] R. Fuentes and J. J. Garcia, "Influence of the tunnel length on the hydraulic modelling of the air entrainment in the flow downstream of a high head gate," in Proceedings of the Symposium on Scale Effects in Modelling Hydraulic Structures, Technische Akademie, Technische Akademie Esslingen, Esslingen, Germany, 1984.

[6] R. G. Serret, "Aeration of outlets with free surface flow Design consideration and computer program application for some constructions," in Proceedings of the International Symposium on New Trends and Guidelines on Dam Safety, Barcelona, Spain, 1998.

[7] J. Schneider, D. Mayr, G. Heigerth, and R. Klasinc, The Model Tests of The Bottom Outlet of The Kárahnjúkar Hydro-Electric Project, Waterpower XV, Chattanooga, Tenn, USA, 2007.

[8] H. Chanson and G. L. Qiao, "Air bubble entrainment and gas transfer at hydraulic jumps," Research report no. CE149, Civil Engineering, University of Queensland, Brisbane, Australia, 1994.

[9] C. Lauchlan, M. Escarameia, R. W. P. May, R. Burrows, and C. Gahan, "Air in pipelines - a literature review," Report no. SR 649, HR Wallingford Ltd., Wallingford, UK, 2005.

[10] O. Pozos Estrada, Investigation on the effects of entrained air, [Ph.D. thesis], University of Stuttgart, Stuttgart, Germany, 2007.

[11] A. A. Ahmed, D. A. Ervine, and E. J. McKeogh, "The process of aeration in closed conduit hydraulic structures," in Proceedings of the Symposium on Scale Effects in Modelling Hydraulic Structures, Technische Akademie, Esslingen, Germany, 1984.

[12] M. Escarameia, C. Dabrowski, C. Gahan, and C. Lauchlan, "Experimental and numerical studies on movement of air in water pipelines," in Report no. SR 661, HR Wallingford Ltd., Wallingford, UK, 2005.

[13] N. Rajaratnam, "Hydraulic Jumps," in Advances in Hydroscience, vol. 4, pp. 197-280, Academic Press, New York, USA, 1967.

[14] P. Wisner, F. N. Mohsen, and N. Kouwen, "Removal of air from water lines by hydraulic means," ASCE Journal of the Hydraulics Division, vol. 101, no. HY2, pp. 243-257, 1975.

[15] S. L. Rabben, H. Els, and G. Rouve, "Investigation on flow aeration at offsets downstream of high-head control structures," in Proceedings of the 20th IAHR Congress, vol. 4, pp. 354-360, Moscow, Russia, 1983.

[16] H. R. Sharma, "Air-Entrainment in high head gated conduits," Journal of the Hydraulics Division, vol. 102, no. HY11, pp. 16291646, 1976.

[17] M. Escarameia, "Investigating hydraulic removal of air from water pipelines," Proceedings of the Institution of Civil EngineersWater Management, vol. 160, no. 1, pp. 25-34, 2007.

[18] J. D. Mortensen, Factors affecting air entrainment of hydraulic jumps within closed conduits, [M.Sc. thesis], All Graduate Theses and Dissertations, Paper 531, Utah State University, 2009.

[19] V. Heller, "Scale effects in physical hydraulic engineering models," Journal of Hydraulic Research, vol. 49, no. 3, pp. 293-306, 2011.

[20] M. Pfister and H. Chanson, "Scale effects in modelling twophase air-water flows," in Proceedings of the 2013 IAHR World Congress, Chengdu, China, 2013.

[21] K. Safavi, A. R. Zarrati, and J. Attari, "Experimental study of air demand in high head gated tunnels," Proceedings of the Institution of Civil Engineers-Water Management, vol. 161, no. 2, pp. 105-111, 2008.

[22] M. R. Najafi and A. R. Zarrati, "Numerical simulation of airwater flow in gated tunnels," Proceedings of the Institution of Civil Engineers-Water Management, vol. 163, no. 6, pp. 289-295, 2010.

[23] M.Zounemat-Kermani and M. Scholz, "Computing air demand using the takagi-sugeno model for dam outlets," Water (Switzerland), vol. 5, no. 3, pp. 1441-1456, 2013.

[24] X. D. Ma, Q. Yang, G. Q. Dai, and J. Xu, "Numerical Simulation of Hydraulic Characteristics of Spillway Tunnel in the Radial Gate Closing Process," in Proceedings of the 2013 IAHR World Congress, Chengdu, China, 2013.

[25] B. Dargahi, "Flow characteristics of bottom outlets with moving gates," Journal of Hydraulic Research, vol. 48, no. 4, pp. 476-482, 2010.

[26] U.S. Army Corps of Engineers, "Engineering and design - vertical lift gates," in Engineer Manual EM 1110-2-2701, Washington, DC, USA, 1997.

[27] ANSYS Inc, ANSYS FLUENT Theory Guide, Canonsburg, Penn, USA, 2011.

[28] C. W. Hirt and B. D. Nichols, "Volume of fluid (VOF) method for the dynamics of free boundaries," Journal of Computational Physics, vol. 39, no. 1, pp. 201-225, 1981.

[29] D. K. H. Ho, K. M. Boyes, and S. M. Donohoo, "Investigation of spillway behavior under increased maximum flood by computational fluid dynamics technique," in Proceedings of the 14th Australasian Fluid Mechanics Conference, Adelaide, Australia, 2001.

[30] J. Chatila and M. Tabbara, "Computational modeling of flow over an ogee spillway," Computers \& Structures, vol. 82, no. 22, pp. 1805-1812, 2004. 
[31] T. Liu and J. Yang, "Three-dimensional computations of waterair flow in a bottom spillway during gate opening," Engineering Applications of Computational Fluid Mechanics, vol. 8, no. 1, pp. 104-115, 2014.

[32] L. Satrapa, M. Broucek, M. Kralik, and M. Zukal, "Gated spillways numerical and physical modelling," in Proceedings of the 25th ICOLD Congress, Stavanger, Norway, 2015.

[33] J. Yang, G. Amnell, and P. Sundqvist, "Storfinnforsen hydropower station - investigations of hydraulic functions of its bottom outlet," Vattenfall R\&D, Project report no. U 08:25, Älvkarleby, Sweden, 2008 (Swedish).

[34] J. Yang, A. Helgesson, and M. Billstein, "Discharge safety of Storfinnforsen dam, hydraulic model tests 2014-15," Vattenfall R\&D, Project report no. U 14:55, Älvkarleby, Sweden, 2015 (Swedish).

[35] J. Yang, J. Larsson, and C. O. Nilsson, "Re-commissioning Storfinnforsens bottom outlet after over 60 years idling," in Proceedings of the ICOLD 2016 Annual Symposium, Johannesburg, South Africa, 2016.

[36] P. Vahdati, "CFD Simulation of water behavior downstream of the Storfinnforsen dam, [M.Sc. thesis]," Tech. Rep., Luleå University of Technology, Luleå, Sweden, 2010.

[37] S. Wu and N. Rajaratnam, "Free jumps, submerged jumps and wall jets," Journal of Hydraulic Research, vol. 33, no. 2, pp. 197212, 1995.

[38] F. Ma, Y. Hou, and P. Prinos, "Numerical calculation of submerged hydraulic jumps," Journal of Hydraulic Research, vol. 39, no. 5, pp. 493-501, 2001.

[39] Y. Shekari, M. Javan, and A. Eghbalzadeh, "Three-dimensional Numerical Study of Submerged Hydraulic Jumps," Arabian Journal for Science and Engineering, vol. 39, no. 10, pp. 69696981, 2014. 


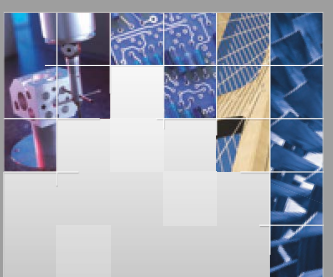

\section{Enfincering}
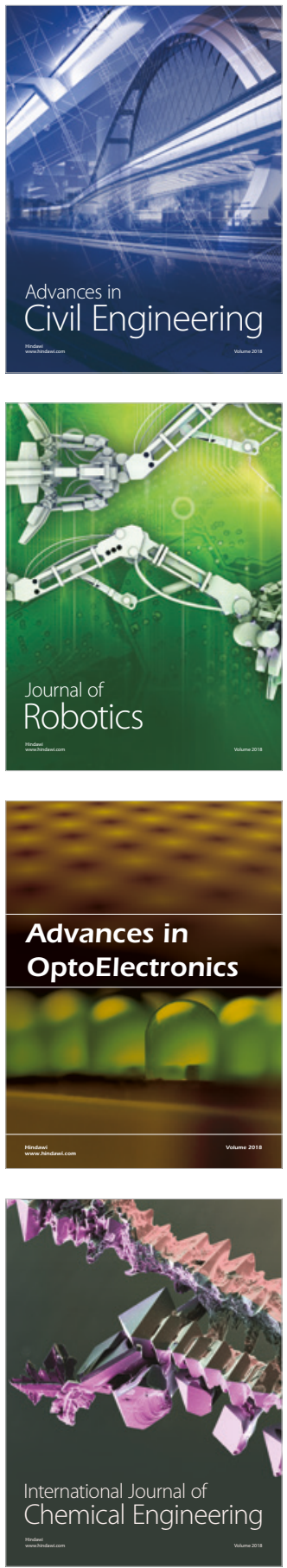

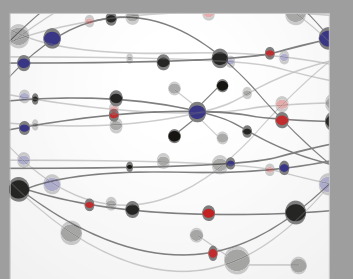

\section{Rotating \\ Machinery}

The Scientific World Journal

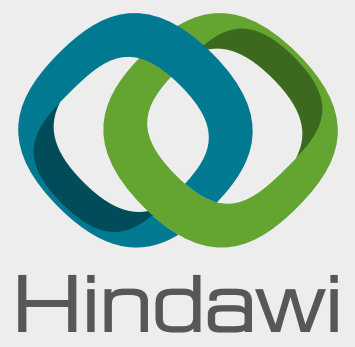

Submit your manuscripts at

www.hindawi.com
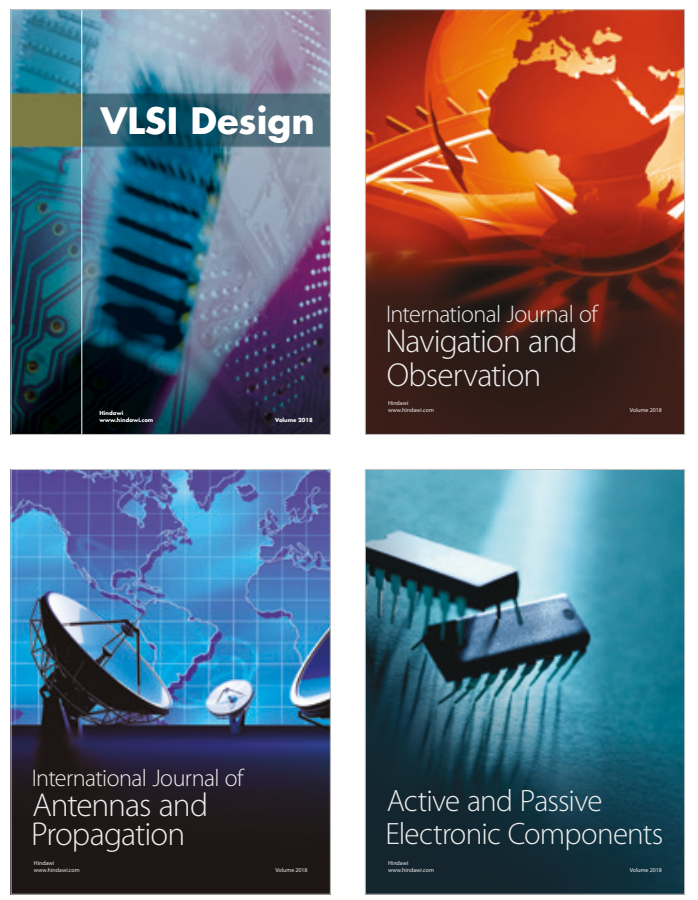
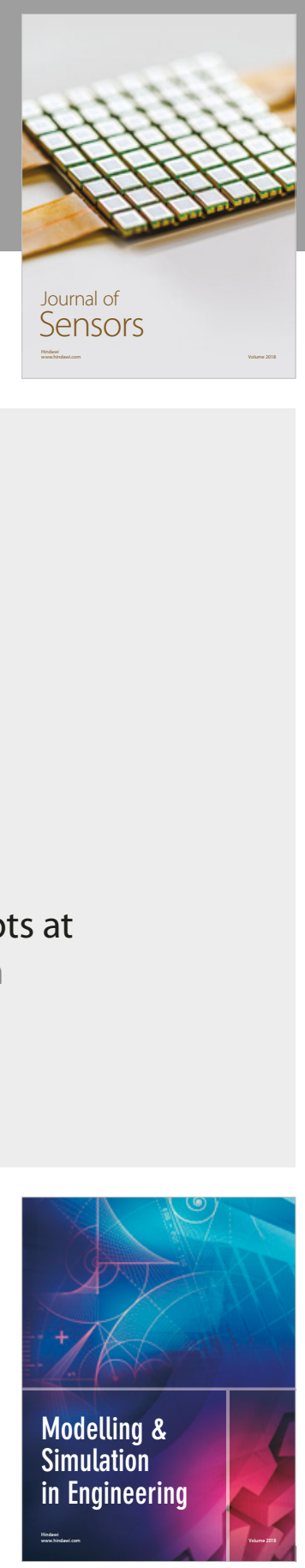

\section{Advances \\ Multimedia}
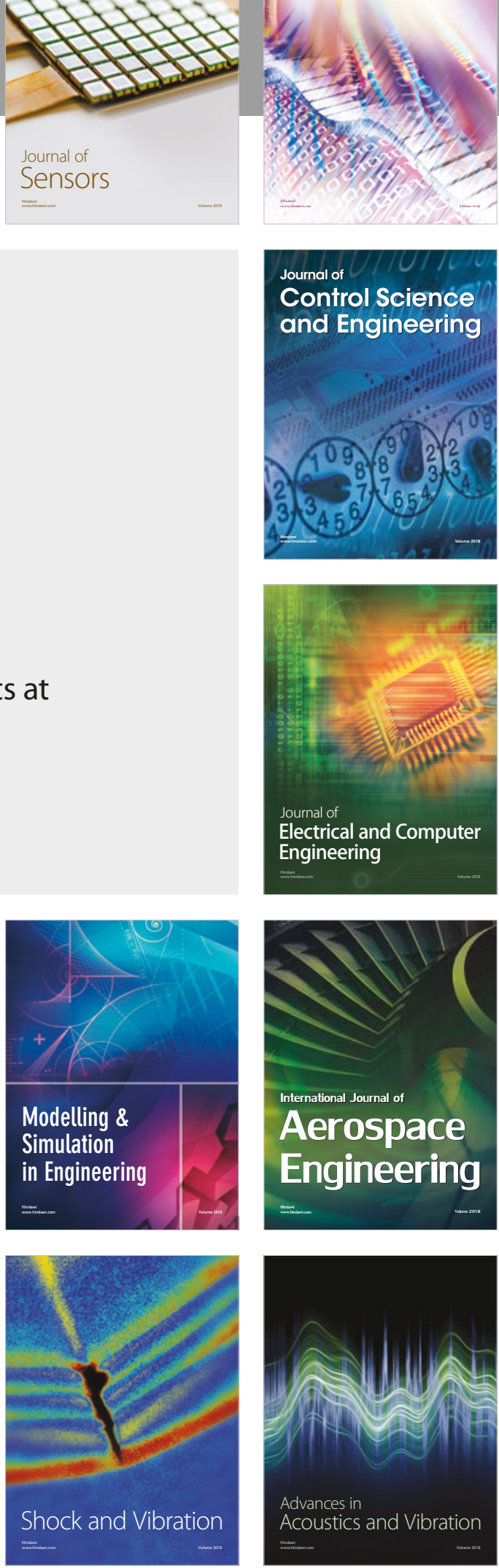